\title{
Pesquisa
}

\section{A EXTENSÃO UNIVERSITÁRIA COMO FATOR DE DESENVOLVIMENTO COMUNITÁRIO ATRAVÉS DE AÇÕES INTEGRADAS DOS CURSOS DA UNIVERSIDADE ESTADUAL VALE DO ACARAU - UVA.}

\author{
Michele da Silva Teixeira (1)
}

\begin{abstract}
Resumo
O artigo apresenta uma breve abordagem histórica da extensão universitária no Brasil, tendo como foco ações integradas da Universidade Estadual Vale do Acaraú - UVA em Crato-Ce, objetivando mostrar como a parceria entre universidade e comunidade pode trazer benefícios e desenvolvimento para a região. Através de pesquisa bibliográfica e coleta de dados realizada por questionários aplicados aos discentes, tivemos a oportunidade de levantar esses dados fomentando um processo de reflexão para a universidade em questão.
\end{abstract}

Palavras-chave: extensão universitária. ações integradas. desenvolvimento comunitário

\section{Introdução}

A extensão universitária está presente na realidade acadêmica, porém ainda pouco explorada em nossa região. Através da identificação de sua importância dentro da Universidade Estadual Vale do Acaraú - UVA em Crato-Ce baseada nos cursos por ela ofertados, vários são os fatores de desenvolvimento comunitário a serem explorados, através da descrição do histórico da pesquisa e extensão no Brasil, bem como uma análise do papel da UVA dentro do contexto social que ela está inserida, tendo como foco ações que possam ser desenvolvidas pelos discentes das quais benefícios serão percebidos na comunidade.

Os alunos e egressos das Universidades em sua maioria desenvolvem trabalhos de conclusão de curso apenas para obtenção do título, e acabam não mensurando o poder que esses projetos têm para modificar o cenário social atual. Tendo em vista que muitos são os conflitos enfrentados pela sociedade para sobrevivência em um mundo capitalista que na maioria das vezes não dão o devido 
acesso as necessidades vitais dos indivíduos que são educação, saúde, lazer, moradia esporte cultura dentre outras que formam o caráter do ser.

Vivemos uma realidade social onde a comunidade encontra-se carente de atenção por parte dos governantes como um todo. Os universitários são detentores de grande parte do conhecimento, e podem a partir deste contexto desenvolver ações integradas com a comunidade para melhorar a atual situação em que vivem. Um estudo desta natureza é extremamente relevante, uma vez que poucos são os pesquisadores da nossa região que abordam na nossa cidade esta temática tão rica, porém pouco explorada.

\section{O que é extensão universitária?}

Pensar no papel da universidade na sociedade caracteriza com êxito o que é a extensão universitária, desde o inicio da história das universidades o tripé extensão não é devidamente explorado como quanto é no papel. A extensão universitária é a resposta que o discente tem o dever de dar a sociedade uma vez aluno ou egresso da universidade, é o que e como ele vai fazer para usufruir de tudo que ele aprendeu e colocar na prática em benefício de um bem comum.

O espaço da universidade tende a priorizar o ensino e a pesquisa, com resultados a garantir a formação profissional dos estudantes. O conceito de extensão, porém, se alia a essas duas grandes bases do ensino superior ao permitir a prática do conhecimento aprendido na academia, buscando uma maior integração com a realidade e as demandas da sociedade. (ANDRADE, 2010, p.02)

As Instituições de Ensino Superior (IES) tendem a explorar dos seus discentes apenas duas das três bases do ensino que são o ensino e a pesquisa, a terceira por sua vez: a extensão universitária acaba sendo "colocada e lado", pois as duas primeiras são as que dão de imediato à sociedade os resultados que elas esperam dos profissionais que são formados em um nível superior: alguém capacitado para assumir uma função dentro de uma organização e garantir a lucrativade da mesma, esquecendo assim o papel social que todos nós devemos ter.

O aluno precisa ter a consciência de que tudo aquilo que ele aprende na universidade não deverá servir apenas para a obtenção de uma titulação, ele deve sentir-se útil e ver brotar os frutos de uma longa jornada de ensino-aprendizagem, uma permanente construção de conhecimento é fundamental para o seu desenvolvimento. Envolver o discente ainda quando está na graduação em programas de pesquisa e extensão, faz com que ele se familiarize não apenas com a teoria mais sim com a prática, alcançando assim resultados eficazes como ser humanos mais conscientes do seu papel na sociedade, pessoas coerentes e seguras de sua profissão, pois tiveram na vivência real a oportunidade de colocar em prática tudo aquilo teorizado em sala de aula. 
Se, antes, cortar uma árvore, fazê-la em pedaços, transformá-las em tábuas e construir mesas e cadeiras podia significar algo pouco mais além do que o trabalho físico mesmo, agora, na "re-ad-miração", estes atas ganham a significação verdadeira que devem ter: a da práxis. A mesa e as cadeiras já não serão nunca mais simplesmente mesas e cadeiras: são algo mais: são produtos do seu trabalho. Aprender a fazê-las melhor, se este fosse o caso, deveria começar por esta descoberta. (FREIRE, 1983, p.63)

Para isso, existem as atividades extensionistas voltadas para a prática de tudo aquilo que o aluno absorve na teoria no seu período de graduação, a partir dessa prática os valores morais e intelectuais ganham embasamento, considerando que a partir do momento que se alia teoria a prática, torna-se concreto tudo aquilo absorvido pelos discentes dentro da sala de aula.

\section{Extensão universitária no Brasil}

Baseado no decreto de número 19.851 de 11 de abril de 1931 surge no Brasil o conceito de extensão universitária, fato esse ocorrido durante o governo de Getúlio Vargas, que trouxe uma verdadeira revolução na educação no que diz respeito as suas atividades de prática universitária.

Art. $1^{\circ} \mathrm{O}$ ensino universitário tem como finalidade: elevar o nível da cultura geral, estimular a investigação científica em quaisquer domínios dos conhecimentos humanos; habilitar ao exercício de atividades que requerem preparo técnico e científico superior; concorrer, enfim, pela educação do indivíduo e da coletividade, pela harmonia de objetivos entre professores e estudantes e pelo aproveitamento de todas as atividades universitárias, para a grandeza na Nação e para o aperfeiçoamento da Humanidade.(VARGAS, 1931, p.01)

Conseguimos perceber que a proposta extensionistas vai muito além de tudo aquilo que é discutido em sala de aula, ela visa aproveitar tudo aquilo que foi aprendido para ajudar a comunidade a se desenvolver. Faz-se necessário a ação dentro e fora do campus universitário, pois temos uma diversidade inserida nesse contexto que pode perfeitamente abranger as necessidades do povo.

Pensar a universidade a partir de seus objetivos básicos de formação profissional, geração de novos conhecimentos e disseminação desses conhecimentos é um processo complexo face à natureza e diversidade do trabalho acadêmico. Inserida neste contexto está a extensão universitária, que apresenta uma diversidade conceitual e prática que interfere expressivamente no "pensar" e no "fazer" no interior da universidade. (SERRANO, 2009, p.01)

Falar em extensão universitária não é apenas conceituar em um papel, termos e expressões que condizem a esta temática, mais sim concretizar na prática por intermédio de ações conjuntas e 
organizadas pela universidade atividades de natureza extensionistas capazes de levar a população a tomar conhecimento do enorme capital intelectual existente dentro das instituições de ensino superior, mostrando ainda suas capacidades de trabalhar em equipe com o povo e para o povo, de forma simples, porém eficaz.

\section{Método}

Toda pesquisa cientifica surge de uma inquietação do ser, a partir deste questionamento o indivíduo busca encontrar soluções através de estudos e pesquisas relacionadas ao problema apontado, esse problema na maioria das vezes de caráter social ou ainda investigativo mediante alguma dúvida que o pesquisador tem em relação a uma temática.

A pesquisa pode ser considerada um procedimento formal com método de pensamento reflexivo que requer um tratamento científico e se constitui no caminho para se conhecer a realidade ou para descobrir verdades parciais. (LAKATOS, 1992, p.42)

Toda pesquisa é relevante uma vez que a partir dela, não só o questionamento do pesquisador terá uma resposta, mais sim a dúvida de tantas outras pessoas que não se dispuseram a trabalhar a pesquisa dentro de suas atividades acadêmicas ou sociais.

Os instrumentos utilizados para coleta de dados foram: Um Questionário de avaliação para alunos da Universidade Estadual Vale do Acaraú - UVA e, uma Entrevista oral sem gravação com os alunos da UVA.

Quanto aos Procedimentos, a priori foi feito uma visita a Universidade Estadual Vale do Acaraú - UVA na cidade de Crato-Ce, para juntamente à coordenação viabilizar o estudo em questão e identificar o número de alunos matriculados aptos a participarem da pesquisa.

Em seguida, foi aplicado o Termo de consentimento livre esclarecido - TCLE, para que os entrevistados possam tomar conhecimento do conteúdo da pesquisa, deixando claro que eles possuem liberdade de responder ou não os questionamentos, sem que haja prejuízo aos mesmos.

Após a confirmação da voluntariedade em participar da pesquisa foram aplicados os questionários escritos, bem como as entrevistas orais.

A análise e interpretação dos dados torna-se possível quando relaciona-se os dados que foram levantados na pesquisa com aquilo que é estudado, viabilizando assim as respostas necessárias para satisfazer o problema da pesquisa. Contudo foram retirados dos questionários e entrevistas aplicados aos discentes da UVA, dados suficientes para mostrar como as atividades de extensão dentro da Universidade Estadual Vale do Acaraú - UVA em Crato-Ce são de extrema relevância para o 
desenvolvimento dos alunos e acima de tudo o desenvolvimento da comunidade. Para esclarecer a análise dos dados foram construídos gráficos e tabelas no programa Microsoft Excel, através deste programa foram viabilizados os testes estatísticos fundamentais para a análise dos dados.

O referido estudo respeitou todos os critérios presentes na resolução 196/96 do Conselho Nacional de Saúde - CNS, (BRASIL, 1996), referente à pesquisa envolvendo seres humanos.

Foi solicitado o termo de Consentimento Livre Esclarecido (TCLE) de todos os que participaram deste estudo

O estudo em questão foi realizado na Universidade Estadual Vale do Acaraú - UVA, localizada à Rua Dom Quintino, 863 centro Crato-Ce, CEP: 63.100-070, e-mail: cariri@idj.com.br, telefone: (88) 3521-1060.

O período de realização do estudo foi de 01 a 19 de outubro de 2012, no período noturno.

\section{Características socioeconômicas do município}

Crato localiza-se no interior do Ceará, faz divisa com o estado do Pernambuco e alguns autores o denominam como "Princesinha do cariri" "Cratinho de Açúcar" e "Oásis do Sertão", por sua riqueza da chapada. Possui uma economia bem diversificada, voltada para agricultura, artesanato, mineração, piscicultura, comércio, feira de agronegócios (Expocrato). É também considerada a capital da cultura por suas riquezas e diversidades de grupos folclóricos e pela sua própria história que traz em seu contexto ilustres como: Bárbara de Alencar, Frei Carlos Maria de Ferrara, dentre outros.

\section{Analise dos Resultados}

\section{Com relação ao papel da Universidade Estadual Vale do Acaraú-UVA frente aos problemas comunitários?}

No capitulo VI da Lei de Diretrizes e Bases - LDB fica bastante claro qual o papel da extensão universitária dentro da Sociedade, quando ele cita em um trecho que um dos seus principais papéis é prestar serviços à comunidade e estabelecer com a mesma uma relação de reciprocidade.

A universidade estadual vale do Acaraú - UVA traz em sua missão a proposta de: Ofertar ensino superior de excelência, de forma inclusiva, flexível e contextualizada, e buscar, por meio da pesquisa e extensão, soluções que promovam a qualidade de vida. Essa qualidade de vida é o foco central de nosso estudo, onde podemos questionar: a quem e como será ofertada essa qualidade de vida? Tendo em vista que a nossa comunidade é extremamente carente de atividades dessa natureza, 
surge aqui uma excelente oportunidade de integrar os alunos e a universidade à comunidade, fazendo valer o tripé da Educação Superior no que tange ao ENSINO, PESQUISA E EXTENSÃO, o último por nos nesse estudo priorizado.

Dentro da sua estrutura de cursos a UVA oferece em seus campos localizados em Sobral e no Cariri (Crato-Juazeiro do Norte que formam o IDJ Cariri).

\begin{tabular}{|c|c|c|}
\hline CURSO & IDJ CARIRI & UVA SOBRAL \\
\hline Administração & $\mathrm{x}$ & $\mathrm{x}$ \\
\hline Biologia & $\mathrm{x}$ & $\mathrm{x}$ \\
\hline Ciências Contábeis & $\mathrm{x}$ & $\mathrm{x}$ \\
\hline Ciências da Computação & & $\mathrm{x}$ \\
\hline Ciências da matemática & & $\mathrm{x}$ \\
\hline Ciências Sociais & $\mathrm{x}$ & $\mathrm{x}$ \\
\hline Direito & & $\mathrm{x}$ \\
\hline Educação Física & $\mathrm{x}$ & $\mathrm{x}$ \\
\hline Enfermagem & & $\mathrm{x}$ \\
\hline Engenharia civil & & $\mathrm{x}$ \\
\hline Filosofia & & $\mathrm{x}$ \\
\hline Física & & $\mathrm{x}$ \\
\hline Geografia & $\mathrm{x}$ & $\mathrm{x}$ \\
\hline História & $\mathrm{x}$ & $\mathrm{x}$ \\
\hline Letras & $\mathrm{x}$ & $\mathrm{x}$ \\
\hline Núcleo de Disciplinas conjuntas & & $\mathrm{x}$ \\
\hline Pedagogia & $\mathrm{x}$ & $\mathrm{x}$ \\
\hline Química & & $\mathrm{x}$ \\
\hline Tecnologia da construção de edifícios & & $\mathrm{x}$ \\
\hline Zootecnia & & $\mathrm{x}$ \\
\hline
\end{tabular}

Fonte: http://www.uvanet.br/cursos

Observando a diversidade de cursos ofertados nos cabe o seguinte questionamento: Porque não se utilizar de todos esses cursos para melhorar a qualidade de vida de nossa realidade social? Não 
vale a pena o aluno somente passar pelos bancos da Universidade sem desempenhar nenhum papel de cidadão consciente de seus direitos e deveres.

É exatamente a partir dessa questão que emerge o papel da Universidade Estadual Vale do Acaraú -UVA: Fomentar nos discentes o desejo de contribuir com essa proposta extensionistas dentro e fora da universidade.

É preciso, na verdade, que a alfabetização de adultos e a pós-alfabetização, a serviço da reconstrução nacional, contribuam para que o povo, tomando mãos e mais a sua história nas mãos, se refaça na feitura da história. Fazer a história é estar presente nela e não simplesmente nela estar representado. (FREIRE, 2011, p.53)

Várias organizações sem fins lucrativos e até mesmo empresas privadas necessitam a todo momento de pessoas qualificadas para darem suporte as suas atividades, haja vista que seus rendimentos não conseguem suportar a demanda de pessoas que vivem em situações que carecem de atenção e cuidados, cabe aqui aos universitários aplicar tudo aquilo que aprenderam na teoria, e é exatamente nesse ponto que surgem as maiores dúvidas e anseios: como? Onde? Quando? Com quanto? Eu irei desenvolver atividades que possam ajudar a comunidade em que estou inserida.

É nesse exato ponto que a Universidade deve estar preparada para dar suporte ao aluno através de orientação e acompanhamento dos projetos de extensão por eles desenvolvidos, acompanhando tornando viáveis essas atividades para que os alunos não desistam no meio do caminho, pois é percebido que quando ocorrem essas atividades no começo existe certa empolgação e a partir dela deve ser trabalhado o discente para não perder o foco nem desistir e isso é possível quando os docentes conseguem inserir na educação também a responsabilidade que cada um tem com a sociedade.

\section{Percepção dos alunos sobre atividades de extensão}

Após o levantamento dos dados através dos questionários aplicados aos docentes da UVA foi feita a compilação dos mesmos, onde foi possível constatar, que a maioria nunca participou dentro da universidade de nenhuma atividade que envolvesse a comunidade conforme mostra o quadro 1 a seguir: 


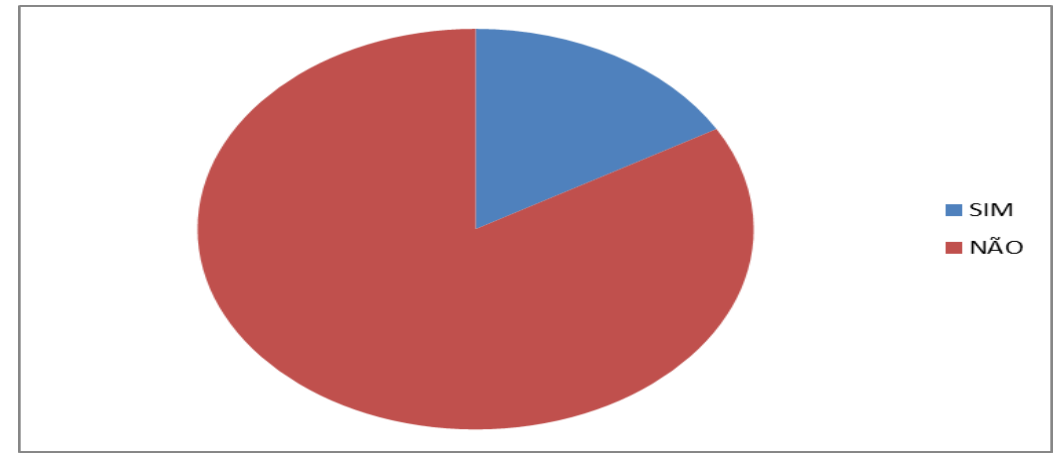

Quadro 1 - Participação em atividades que envolva a comunidade Fonte: Pesquisa direta/2012

Ainda, nas entrevistas orais que tivemos a oportunidade de realizar, podemos perceber que os alunos são sedentos de informações sobre atividades de extensão, notou-se ainda um interesse relevante em participar dessas atividades, pois eles apesar de em sua maioria serem bastante jovens possuem o senso de responsabilidade social e conseguem avaliar que sua contribuição para sociedade é importante e fundamental para o crescimento da mesma.

Percepção dos alunos sobre os benefícios de ações de intervenção junto à comunidade.

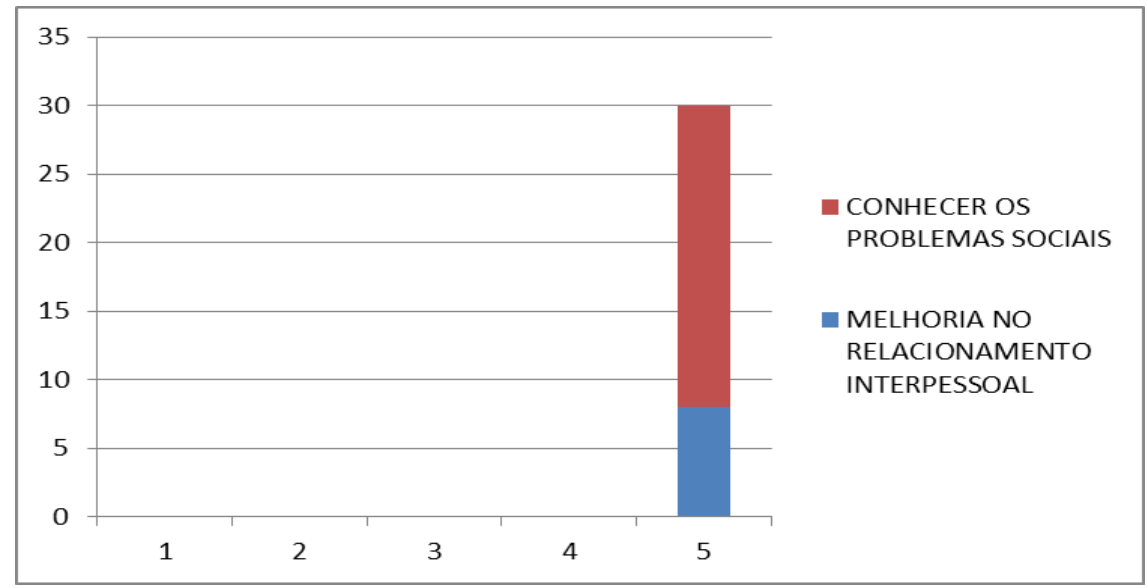

Quadro 2 - Gráfico da percepção dos alunos sobre atividades junto a comunidade Fonte: Pesquisa direta/2012

Nota-se através do quadro 2 resultados do questionamento feito aos alunos onde percebe-se o interesse em fazer atividades junto à comunidade, pois conhecem de perto e possuem a consciência que essas atividades trarão melhorias no relacionamento interpessoal e possam estar cada vez mais cientes dos problemas sociais que assolam a realidade em que estão inseridos. 
Ações como: visita a áreas de risco dentro da cidade, a hospitais, ongs e instituições sem fins lucrativos podem ser desenvolvidas por esses alunos, todos eles em entrevista oral deixaram claro o interesse em conhecer e ajudar essas instituições.

\section{Considerações Finais}

O papel do docente dentro das instituições de ensino não deve ser apenas para transmitir conhecimento, uma vez que o mesmo deve ter a consciência da sua função sabendo assim que ela não concerne apenas a lecionar uma disciplina, ele deve ser focado principalmente na formação do pensamento crítico dos alunos a fim de possibilitar a modificação do atual cenário da sociedade.

Atividades de extensão dentro das universidades fazem com que os discentes despertem o interesse em envolver-se em questões sociais, uma vez que há de certa forma um descaso dos governantes para com os indivíduos, os alunos acabam interagindo e a partir dessa entrega são capazes de modificar cenários de sofrimento e descaso sentidos pela população.

Foi possível através deste estudo, descrever o histórico da extensão no Brasil e a partir dessa descrição analisar qual o papel da Universidade estadual vale do Acaraú- UVA dentro do contexto social que ela está inserida, apontando posteriormente ações que possam ser desenvolvidas pelos discentes da UVA.

\section{Referencias}

ANDRADE, Nhayana de Freitas. A importância das práticas extensionistas como forma de promoção e universalização da Instituição PUC Minas. Belo Horizonte, 2010. Artigo disponível em: http://www.pucminas.br/documentos/trabalhos_aprovados_vi_seminario.pdf.Acesso em: 03/07/2012.

FREIRE, Paulo. Extensão ou comunicação? 7. ed. Rio de Janeiro: Paz e terra, 1983.

GIL, Antônio Carlos. Métodos e técnicas de pesquisa social. 5.ed. São Paulo: Atlas, 1999., A importância do ato de ler em três artigos que se completam. 51. ed. São Paulo:

Cortez, 2011. 
ROHDEN, Huberto. Educação do homem integral. São Paulo: Martin Claret, 1998.

SCOZ, Beatriz. Psicopedagogia e realidade escolar: o problema escolar e de aprendizagem.17.ed. Rio de Janeiro: Vozes, 2011.

SERRANO, Maria Souto Maior. Conceitos de extensão universitária: um diálogo com Paulo Freire. Rio de Janeiro, 2010. Disponível em:http://www.prac.ufpb.br/copac/extelar /atividades/discussao/artigos/conceitos_de_extensao_universitaria.pdf. Acesso em: 04/07/2012

VARGAS, Getúlio. DECRETO No 19.851, DE 11 DE ABRIL DE 1931.Brasília, 1931.Disponível em: http://www.planalto.gov.br/ccivil_03/decreto/1930-1949/D19851.htmimpressao.htm.Acesso em: 07/08/2012

\section{Sobre a Autora:}

1. Michele da Silva Teixeira é Bacharel em Administração de Empresas e Pós-Graduada em Docência do Ensino Superior pela Faculdade Vale do Jaguaribe - FVJ.

E-mail: michelesilvaadm@bol.com.br

\section{Como citar este artigo (Formato ISO):}

TEIXEIRA, M.S. O A extensão universitária como fator de desenvolvimento comunitário através de ações integradas dos cursos da Universidade Estadual Vale do Acaraú - UVA. Id on Line Revista de Psicologia, Novembro de 2012, vol.1, n.18, p. 86-95. ISSN 1981-1189. 